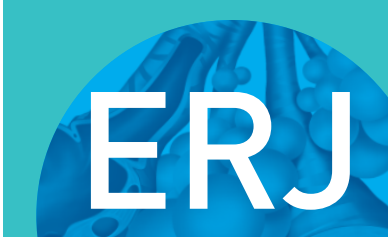

open research

\title{
Amyloidosis of the respiratory system: 16 patients with amyloidosis initially diagnosed ante mortem by pulmonologists
}

\author{
Masami Yamada ${ }^{1}$, Noboru Takayanagi ${ }^{1}$, Hideaki Yamakawa ${ }^{2,3}$, \\ Takashi Ishiguro', Tomohisa Baba², Yoshihiko Shimizu', Koji Okudela ${ }^{5}$, \\ Tamiko Takemura ${ }^{6}$ and Takashi Ogura ${ }^{1}$
}

Affiliations: 'Dept of Respiratory Medicine, Saitama Cardiovascular and Respiratory Center, Saitama, Japan. ${ }^{2}$ Dept of Respiratory Medicine, Kanagawa Cardiovascular and Respiratory Center, Yokohama, Japan. ${ }^{3}$ Dept of Respiratory Medicine, Saitama Red Cross Hospital, Saitama, Japan. ${ }^{4}$ Dept of Diagnostic Pathology, Saitama Cardiovascular and Respiratory Center, Saitama, Japan. ${ }^{5}$ Dept of Pathobiology, Yokohama City University Graduate School of Medicine, Yokohama, Japan. ${ }^{6}$ Dept of Pathology, Japanese Red Cross Medical Center, Tokyo, Japan.

Correspondence: Masami Yamada, Dept of Respiratory Medicine, Saitama Cardiovascular and Respiratory Center, 1696 Itai, Kumagaya, Saitama 360-0105, Japan. E-mail: masami_yajikei.ac.jp

\section{ABSTRACT}

Background: Ante mortem diagnosis of amyloidosis of the respiratory system is rare. Few data are available regarding clinical presentation, precursor proteins, diagnostic procedures, comorbidities, complications, and outcome. We assessed clinical features of a series of patients with amyloidosis of the respiratory system in two Japanese centres.

Methods: Medical records of 16 patients with amyloidosis of the respiratory system were retrospectively analysed. Amyloid was diagnosed by polarisation microscopy using Congo red-stained tissue specimens and classified immunohistochemically.

Results: Median patient age was 71 years, and median follow-up period was 5 years. Immunoglobulin light-chain (AL)- $\lambda$ amyloidosis was found in eight and AL- $\kappa$ in five patients. Two patients harboured wild-type transthyretin and one harboured serum amyloid A-derived amyloid. Five different forms of amyloidosis of the respiratory system were observed: nodular pulmonary amyloidosis (seven patients), diffuse alveolar-septal amyloidosis (five), mediastinal lymph node amyloidosis (three), tracheobronchial amyloidosis (one), and pleural amyloidosis (one). One patient had diffuse alveolar-septal amyloidosis and mediastinal lymph node amyloidosis. Three of five patients with diffuse alveolar-septal amyloidosis were diagnosed by transbronchial lung biopsy as having concurrent diffuse alveolar haemorrhage or pneumocystis pneumonia. Two of three patients with mediastinal lymph node amyloidosis were diagnosed by endobronchial ultrasound-guided transbronchial needle aspiration.

Conclusions: Not only nodular pulmonary amyloidosis, diffuse alveolar-septal amyloidosis, and tracheobronchial amyloidosis but also mediastinal lymph node amyloidosis and pleural amyloidosis should be considered in the differential diagnosis of amyloidosis of the respiratory system. Useful diagnostic methods include transbronchial lung biopsy for diffuse alveolar-septal amyloidosis and endobronchial ultrasound-guided transbronchial needle aspiration for mediastinal lymph node amyloidosis.

@ERSpublications

Not only nodular, diffuse alveolar-septal and tracheobronchial amyloidosis but also mediastinal lymph node and pleural amyloidosis should be considered in the differential diagnosis of amyloidosis of the respiratory system https://bit.ly/2ZfZcxo

Cite this article as: Yamada $\mathrm{M}$, Takayanagi $\mathrm{N}$, Yamakawa $\mathrm{H}$, et al. Amyloidosis of the respiratory system: 16 patients with amyloidosis initially diagnosed ante mortem by pulmonologists. ERJ Open Res 2020; 6: 00313-2019 [https://doi.org/10.1183/23120541.00313-2019].

Received: 13 Nov 2019 | Accepted after revision: 8 May 2020

Copyright $\odot$ ERS 2020. This article is open access and distributed under the terms of the Creative Commons Attribution Non-Commercial Licence 4.0 


\section{Introduction}

Amyloidosis is a disorder caused by insoluble misfolded autologous protein and its extracellular deposition, which result in organ dysfunction [1]. Different amyloid types can show different clinical presentations depending on organ involvement and deposition pattern [2]. Although there are 36 known extracellular fibril proteins in humans [2], the fibril proteins that are most commonly encountered include immunoglobulin light-chain (AL), serum amyloid A (AA), and transthyretin (ATTR). In over 7000 consecutive patients reviewed at the UK National Amyloidosis Centre, 60\% had AL amyloidosis, 10\% had AA amyloidosis, 10\% had hereditary ATTR amyloidosis, $8 \%$ had wild-type ATTR amyloidosis, $10 \%$ had localised amyloidosis, and only $0.5 \%$ had other types [3]. AL amyloidosis can occur as a localised or systemic variant. ATTR amyloidosis occurs as a hereditary form caused by a point mutation in the TTR gene (ATTRm) or as a wild-type variant (ATTRwt). AA amyloidosis can result from chronic inflammatory disease and chronic infection [3].

Amyloidosis of the respiratory system may be localised or a part of systemic amyloidosis $[4,5]$. It can appear in five different forms: nodular pulmonary amyloidosis, diffuse alveolar-septal amyloidosis, tracheobronchial amyloidosis, mediastinal lymph node amyloidosis, and pleural amyloidosis [6-16]. Because involvement of the respiratory system is relatively common but rarely symptomatic [6], many patients with pulmonary amyloidosis are diagnosed at autopsy [15]. In a nationwide survey of 741 Japanese patients with systemic AL amyloidosis, only 12 (1.6\%) were diagnosed by lung biopsy [17]. Due to the many different amyloid proteins and forms, differential diagnoses are broad and difficult. Because of its rarity, we present our experience with amyloidosis of the respiratory system diagnosed ante mortem by pulmonologists at two Japanese cardiovascular and respiratory centres.

\section{Methods}

Patients

We retrospectively reviewed the medical records of 16 patients with biopsy-proven amyloidosis of the respiratory system between 1999 and March 2018 at Saitama Cardiovascular and Respiratory Center, Saitama, Japan, or the Department of Respiratory Medicine, Kanagawa Cardiovascular and Respiratory Center, Yokohama, Japan. The first diagnosis of amyloidosis in each patient was made based on biopsy results of the respiratory system. Clinical characteristics and pulmonary function data were obtained at the diagnosis of amyloidosis.

\section{Histology and immunohistochemistry}

All tissue specimens were fixed in formalin. Serial sections were stained with haematoxylin and eosin, Congo red, and immunohistochemical stains. Apple-green birefringence under polarised light in Congo red-stained sections is considered the gold standard for identifying a substance as amyloid. Major amyloid subtypes can be identified by immunohistochemistry. Antibodies are readily available for $\kappa$ and $\lambda$ light chains, serum amyloid A, ATTR (pre-albumin), apolipoprotein A-I, and anti-human $\beta$-2-microglobulin. Congo red and immunohistochemical staining were performed at the Amyloidosis Medical Practice Center, Kumamoto University Hospital, Kumamoto, Japan, or the Department of Medicine (Neurology and Rheumatology), Shinshu University School of Medicine, Japan (amyloidosis referral centre). All patients with ATTR amyloidosis underwent genetic testing of the TTR gene. If no mutations were found, these patients were diagnosed as having ATTRwt amyloidosis.

\section{Definitions}

Monoclonal gammopathy of undetermined significance (MGUS) was diagnosed if patients had a serum M-protein $<3 \mathrm{~g} \cdot \mathrm{dL}^{-1}$, bone marrow clonal plasma cells $<10 \%$, absence of multiple myeloma (MM)-related end-organ damage (CRAB symptoms: hypercalcemia, renal insufficiency, anaemia, and bone lesions), and absence of Waldenström macroglobulinemia.

Localised amyloidosis of the respiratory system was defined as amyloid deposits confined to the respiratory system. Systemic amyloidosis was diagnosed when amyloid deposits were identified both within the respiratory system and outside the thorax. Bilateral carpal tunnel syndrome constituted carpal tunnel involvement [18].

Definitions of deposition patterns are as follows [4-6]. Diffuse alveolar-septal amyloidosis is characterised by the presence of amyloid deposits in the alveolar septa. Nodular pulmonary amyloidosis is defined as tumefactive amyloid deposits involving the lungs. Tracheobronchial amyloidosis is characterised by amyloid deposition in the tracheobronchial tree. Amyloidosis of the pleura and mediastinal lymph node amyloidosis are defined if thoracoscopic pleural biopsy, endobronchial ultrasound-guided transbronchial needle aspiration (EBUS-TBNA) from a mediastinal lymph node, or surgical mediastinal lymph node biopsy revealed amyloid, respectively. 


\section{Study design}

Clinical data were collected from medical records. Patients were followed through December 2018 or until death before December 2018. Survival status was determined from medical records and/or telephone interviews. Institutional review boards from The Saitama Cardiovascular and Respiratory Center (no. 2018028) and Kanagawa Cardiovascular and Respiratory Center (no. KCRC-17-0026) approved this study.

\section{Results}

\section{Patient characteristics (table 1)}

The median age of the 16 patients studied was 71 years. Seven patients (43.8\%) had nodular pulmonary amyloidosis, five $(31.3 \%)$ had diffuse alveolar-septal amyloidosis, three (18.8\%) had mediastinal lymph node amyloidosis, and one each $(6.3 \%)$ had tracheobronchial amyloidosis and pleural amyloidosis. One

TABLE 1 Demographics, localised or systemic variant, precursor protein, $M$-protein, free light-chain $\kappa / \lambda$ ratio, and pulmonary function of 16 patients with amyloidosis of the respiratory system

\begin{tabular}{|c|c|c|c|c|c|c|c|c|}
\hline $\begin{array}{l}\text { No./sex/ } \\
\text { age }\end{array}$ & $\begin{array}{l}\text { Systemic/localised } \\
\text { (CT findings: } \\
\text { single/multiple or } \\
\text { DASA] or organ } \\
\text { involvement }\end{array}$ & $\begin{array}{l}\text { Precursor } \\
\text { protein }\end{array}$ & $\begin{array}{c}\text { M-protein/free } \\
\text { light-chain } \kappa / \lambda \\
\text { ratio } \\
\text { (n: } 0.25-1.80 \text { ) }\end{array}$ & $\begin{array}{l}\text { Clinical } \\
\text { presentation }\end{array}$ & $\begin{array}{l}\text { Smoking: } \\
\text { pack-years }\end{array}$ & Comorbidities & $\begin{array}{c}\text { FVC } \\
\% \\
\text { pred }\end{array}$ & $\begin{array}{l}\mathrm{FEV}_{1} \\
\mathrm{FVC}\end{array}$ \\
\hline $1 / M / 50$ & $\begin{array}{l}\text { L: Lung (single } \\
\text { nodule) }\end{array}$ & $A L-\lambda$ & $(-) / N E$ & Asymptomatic & 15 & None & $66 \%$ & $86 \%$ \\
\hline $2 / F / 69$ & $\begin{array}{l}\text { L: Lung (single } \\
\text { nodule) }\end{array}$ & $A L-\lambda$ & $\lg G-\lambda / N E$ & Asymptomatic & None & MGUS, DM & $137 \%$ & $71 \%$ \\
\hline $3 / M / 57$ & $\begin{array}{l}\text { L: Lung (multiple } \\
\text { nodules) }\end{array}$ & $A L-\lambda$ & $(-) / N E$ & Asymptomatic & 10 & None & $113 \%$ & $71 \%$ \\
\hline 4/M/74 & $\begin{array}{l}\text { L: Lung (multiple } \\
\text { nodules) }\end{array}$ & $A L-\kappa$ & $\lg G-\kappa / N E$ & Asymptomatic & 10 & $\begin{array}{l}\text { Pulmonary MALT } \\
\text { lymphoma, MGUS }\end{array}$ & $119 \%$ & $69 \%$ \\
\hline $5 / F / 60$ & $\begin{array}{l}\text { L: Lung (multiple } \\
\text { nodules) }\end{array}$ & $A L-\kappa$ & $(-) / N E$ & Asymptomatic & None & Sjögren's syndrome & $115 \%$ & $79 \%$ \\
\hline 6/F/72 & $\begin{array}{l}\text { L: Lung (multiple } \\
\text { nodules) }\end{array}$ & $A L-\kappa$ & $\mathrm{NE} / \mathrm{NE}$ & Asymptomatic & None & $\begin{array}{l}\text { Sjögren's syndrome, } \\
\text { RA, NSIP, } \\
\text { bronchiolitis }\end{array}$ & $72 \%$ & $78 \%$ \\
\hline 7/M/71 & $\begin{array}{l}\text { L: Lung (multiple } \\
\text { nodules) }\end{array}$ & $A L-\lambda$ & $(-) / N E$ & $\begin{array}{l}\text { Diverticulitis of } \\
\text { colon }\end{array}$ & 49 & None & $89 \%$ & $62 \%$ \\
\hline 8/M/73 & L: Trachea-bronchus & $A L-\kappa$ & $(-) / N E$ & $\begin{array}{c}\text { Bronchoscopy at } \\
\text { CHP }\end{array}$ & None & $\mathrm{CHP}$ & $98 \%$ & $76 \%$ \\
\hline $9 / F / 63$ & $\begin{array}{l}\text { L: Mediastinal lymph } \\
\text { node }\end{array}$ & $A L-\lambda$ & $\lg G-\lambda / 5.73$ & Asymptomatic & None & MGUS & $83 \%$ & $75 \%$ \\
\hline $10 / M / 61$ & L: Pleura & $A L-\kappa$ & $\begin{array}{c}\text { Bence Jones-к/ } \\
\text { NE }\end{array}$ & $\begin{array}{l}\text { Dyspnoea, } \\
\text { pleural effusion }\end{array}$ & 60 & $\begin{array}{l}\text { MM, MM kidney, } \\
\text { myeloma cell } \\
\text { invasion to pleura }\end{array}$ & NE & NE \\
\hline 11/F/72 & $\begin{array}{l}\text { S: Lung (DASA), } \\
\text { mediastinal lymph } \\
\text { node, pleura, heart }\end{array}$ & $A L-\lambda$ & $(-) / 0.15$ & Dyspnoea & None & None & $73 \%$ & $85 \%$ \\
\hline 12/F/71 & $\begin{array}{l}\text { S: Lung (DASA), } \\
\text { kidney, heart, } \\
\text { rectum }\end{array}$ & $A L-\lambda$ & $\begin{array}{l}\lg G-\lambda, \text { Bence } \\
\text { Jones- } \lambda / N E\end{array}$ & $\begin{array}{l}\text { Haemosputum, } \\
\text { cough, dyspnoea }\end{array}$ & None & $\begin{array}{l}\text { MM, cerebral } \\
\text { infarction }\end{array}$ & $74 \%$ & $80 \%$ \\
\hline 13/F/62 & $\begin{array}{l}\text { S: Lung (DASA), } \\
\text { kidney, heart }\end{array}$ & AA & $(-) / N E$ & $\begin{array}{c}\text { Fever, dyspnoea } \\
\text { of PCP }\end{array}$ & None & RA、PCP & NE & NE \\
\hline 14/M/79 & $\begin{array}{l}\text { S: Lung (DASA), heart, } \\
\text { carpal tunnel }\end{array}$ & ATTRwt & $\lg G-\kappa / N E$ & Haemosputum & 35 & $\begin{array}{l}\text { ATTRwt, MGUS, AF, } \\
\text { pacemaker, carpal } \\
\text { tunnel syndrome }\end{array}$ & $85 \%$ & $72 \%$ \\
\hline $15 / F / 84$ & S: Lung (DASA), heart & ATTRwt & $(-) / 0.94$ & Asymptomatic & None & Lung cancer & $55 \%$ & $73 \%$ \\
\hline 16/M/75 & $\begin{array}{l}\text { S: Mediastinal lymph } \\
\text { node, kidney, heart, } \\
\text { rectum }\end{array}$ & $A L-\lambda$ & $\begin{array}{l}\operatorname{Ig} M-\lambda, \text { Bence } \\
\text { Jones- } \lambda / 0.05\end{array}$ & Dyspnoea & 50 & $\begin{array}{l}\text { Waldenström } \\
\text { macroglobulinemia, } \\
\text { DM }\end{array}$ & $106 \%$ & $75 \%$ \\
\hline
\end{tabular}

CT: computed tomography; DASA: diffuse alveolar-septal amyloidosis; FVC: forced vital capacity; FEV 1 : forced expiratory volume in 1 s/FVC ratio; L: localised; S: systemic; AL: immunoglobulin-derived light-chain; NE: not examined; MGUS: monoclonal gammopathy of undetermined significance; DM: diabetes mellitus; MALT: mucosa-associated lymphoid tissue; RA: rheumatoid arthritis; NSIP: nonspecific interstitial pneumonia; CHP: chronic hypersensitivity pneumonitis; MM: multiple myeloma; PCP: pneumocystis pneumonia; ATTRwt: wild-type transthyretin amyloidosis; AF: atrial fibrillation. 
patient had both alveolar-septal amyloidosis and mediastinal lymph node amyloidosis. AL amyloid of $\lambda$-light-chain origin (AL $\lambda$ ) was found in eight $(53.3 \%)$ patients and that of $\kappa$-light-chain origin (ALK) in five $(33.3 \%)$ patients. The 10 patients with localised amyloidosis had a form of AL amyloidosis. On the other hand, a systemic form was found in the remaining six patients: ATTRwt in two (12.5\%) patients, AA in one $(6.3 \%)$ patient, and $\mathrm{AL}$ amyloidosis in three (18.8\%) patients.

Information on monoclonal (M)-protein was available from 15 patients. Of the 10 patients with local AL amyloidosis, 4 (30\%) had M-protein. Of the three patients with systemic AL amyloidosis, two (30\%) had M-protein, and the other patient had an abnormal serum-free light-chain $\kappa / \lambda$ ratio of 0.15 . The patient with AA amyloidosis had no M-protein, but one of the two patients with ATTRwt amyloidosis did have M-protein. Additional information obtained about the M-protein type showed three patients with an $\operatorname{IgG} \lambda$ M-protein, two with an $\operatorname{IgG\kappa }$ M-protein, one with an $\operatorname{IgM} \lambda$ M-protein, one with a Bence Jones $\kappa$-type M-protein, and one with a Bence Jones $\lambda$-type M-protein. In all six of the patients with AL amyloidosis with M-protein, the M-protein light-chain matched the amyloid light-chain origin.

\section{Clinical presentations (table 1)}

Of the seven patients with nodular pulmonary amyloidosis, six were asymptomatic. Exploration of the five patients with pulmonary alveolar-septal amyloidosis showed two patients with diffuse alveolar haemorrhage, one with pneumocystis pneumonia (PCP), one with dyspnoea, and one with an asymptomatic coin lesion of lung cancer. Clinically, amyloidosis was not considered in the differential diagnoses of ATTRwt amyloidosis patient no. 14 with diffuse alveolar haemorrhage (DAH), ATTRwt amyloidosis patient no. 15 with lung cancer, and AA amyloidosis patient no. 13 with PCP. Patient no. 9 with mediastinal lymph node amyloidosis was asymptomatic. Patient no. 8 with tracheobronchial amyloidosis was diagnosed as having an underlying chronic hypersensitivity pneumonitis at the bronchoscopy performed for bronchoalveolar lavage. Patient no. 10 with pleural amyloidosis had dyspnoea and pleural effusion.

\section{Comorbidities (table 1)}

Of the seven patients with nodular pulmonary amyloidosis, two had Sjögren's syndrome, two had MGUS, and one had pulmonary extranodal marginal zone lymphoma of mucosa-associated lymphoid tissue (MALT) lymphoma. Of the five patients with diffuse alveolar-septal amyloidosis, one with AL amyloidosis had MM, one with AA amyloidosis had rheumatoid arthritis (RA), and one with ATTRwt amyloidosis had atrial fibrillation, carpal tunnel syndrome, and MGUS. Among the three patients with mediastinal lymph node amyloidosis, one had Waldenström macroglobulinemia, one had MGUS, and one had no comorbidities.

\section{Computed tomography findings (table 2)}

In the seven patients with nodular pulmonary amyloidosis, the majority had multiple nodules ranging in size from 10 to $30 \mathrm{~mm}(\mathrm{n}=5$ of 7 ) and the minority had a single nodule ( $\mathrm{n}=2$ of 7 ). Additionally, four of these patients had multiple cysts and two had calcifications (figure 1, patient no. 6). Of the five patients with diffuse alveolar-septal amyloidosis, two patients with DAH had a haematological disorder (i.e. MM and MGUS) (figure 2, patient no. 14), and one patient with PCP had RA. These patients had computed tomography (CT) findings consistent with these underlying disorders (DAH, PCP), and after these disorders improved, all associated CT findings disappeared. Patient no. 15 with diffuse alveolar-septal amyloidosis and lung cancer only had CT findings consistent with lung cancer without apparent parenchymal change. Patient no. 9 with mediastinal lymph node amyloidosis had mediastinal and hilar lymphadenopathy with calcification (figure 1, patient no. 9). Patient no. 11 with both alveolar-septal amyloidosis and mediastinal lymph node amyloidosis showed bilateral pleural effusion, mediastinal lymphadenopathy, and interlobular septal thickening (figure 1, patient no. 11). CT findings showed bilateral pleural effusion and pleural thickening in patient no. 10 with pleural amyloidosis (figure 3). Tracheobronchial thickening in the patient with tracheobronchial amyloidosis, the histological findings of which were consistent with underlying chronic hypersensitivity pneumonitis (i.e. predominantly airway-centred inflammation with diffuse fibrotic change with poorly formed non-necrotising granulomas), showed multifocal submucosal plaques revealed by bronchoscopy (figure 1, patient no. 8).

\section{Diagnostic procedures (table 2)}

All seven patients with nodular pulmonary amyloidosis were diagnosed by video-assisted thoracoscopic lung biopsy (VATS-LB). Of the five patients with diffuse alveolar-septal amyloidosis, three were diagnosed by transbronchial lung biopsy (TBLB), one patient was diagnosed by the pathological findings of VATS lobectomy for lung cancer, and the other patients with concomitant mediastinal lymph node amyloidosis were diagnosed by VATS-LB and VATS mediastinal lymph node biopsy. Two other patients with 
TABLE 2 CT findings, diagnostic procedures, therapy, complications, and survival of 16 patients with amyloidosis of the respiratory system

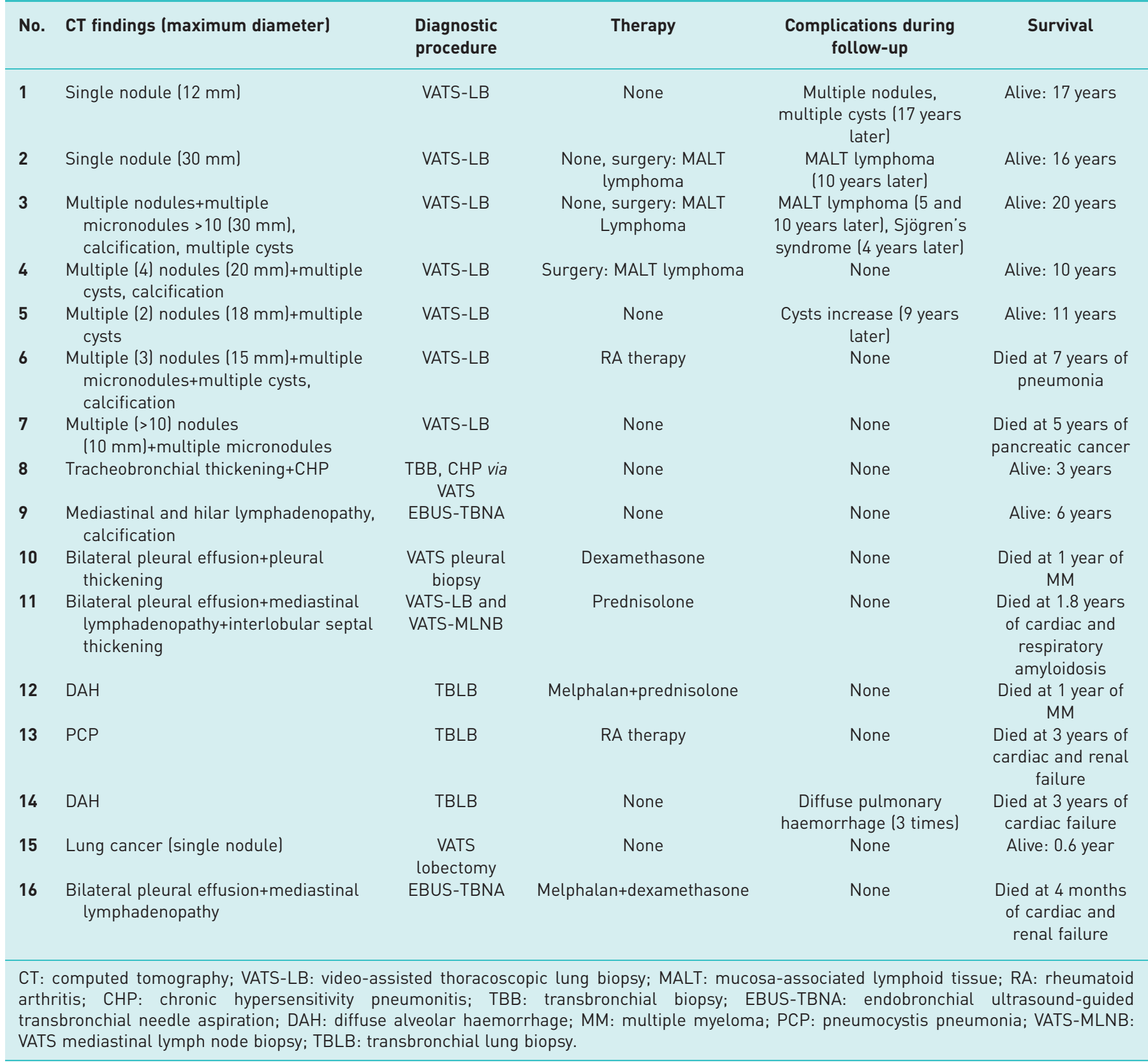

mediastinal lymph node amyloidosis were diagnosed by EBUS-TBNA. One patient with pleural amyloidosis was diagnosed by VATS pleural biopsy.

\section{Therapy (table 2)}

Two patients with MM and one patient with Waldenström macroglobulinemia were treated targeting these underlying disorders. One patient with diffuse alveolar-septal amyloidosis received prednisolone with no effect. Two patients with RA were treated targeting the RA. Pulmonary MALT lymphoma was resected surgically in three patients.

\section{Complications during the follow-up period}

Of the seven patients with nodular pulmonary amyloidosis, two patients developed pulmonary MALT lymphoma, one patient developed Sjögren's syndrome, one patient with a single nodule at diagnosis developed multiple nodules and multiple cysts 17 years later, and in one patient with multiple nodules and 


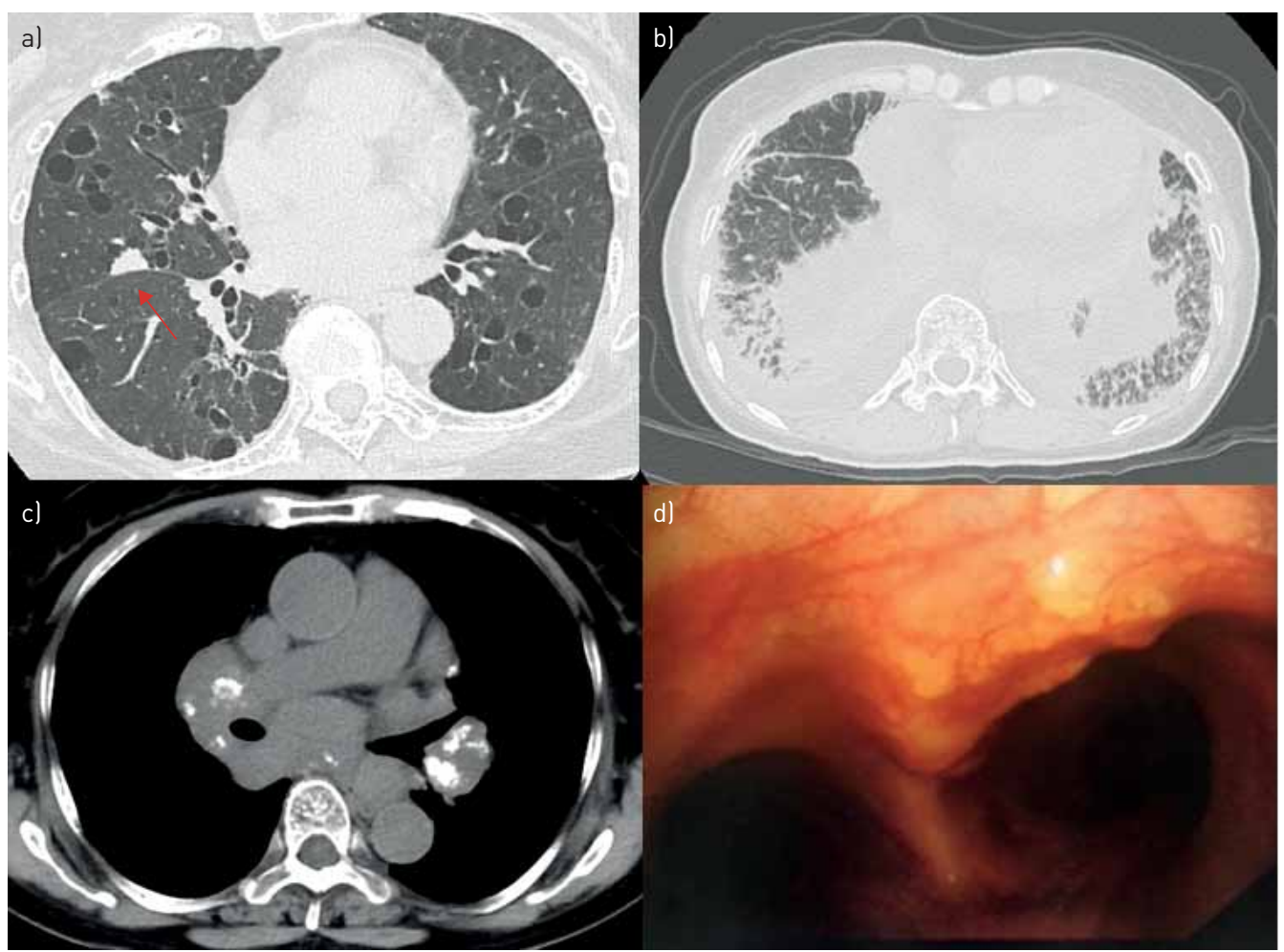

FIGURE 1 Axial high-resolution computed tomography (CT) images of the lung of patients a) no. 6 and b) no. 11, and c) mediastinal (patient no. 9) windows, and d) bronchoscopic appearance (patient no. 8). Patient no. 6 had nodular pulmonary amyloidosis and CT findings showing multiple nodules (red arrow) and multiple cysts. Patient No. 11 had pulmonary alveolar-septal amyloidosis and mediastinal amyloidosis, with CT findings showing bilateral pleural effusion and interlobular septal thickening. Patient no. 9 had mediastinal lymph node amyloidosis and CT findings showing mediastinal and hilar lymphadenopathy with calcification. Patient no. 8 had tracheobronchial amyloidosis and submucosal infiltration with multiple yellow amyloid deposits on the distal tracheal wall on bronchoscopy.

multiple cysts, the diameters of the multiple cysts increased. One patient with ATTRwt amyloidosis who initially presented with DAH suffered recurrence of DAH three times.

\section{Survival data (table 2)}

The median follow-up period was 5 years (range 0.3-20 years). Of the seven patients with nodular pulmonary amyloidosis, five were alive at 10 to 20 years, and the other two patients died of pneumonia or pancreatic cancer, respectively. Other than one patient with only a half-year follow-up period, the other four patients with diffuse alveolar-septal amyloidosis died of amyloidosis or MM within 3 years. Patient no. 9 with local mediastinal lymph node amyloidosis was alive at 6 years, but patient no. 15 with mediastinal lymph node amyloidosis and Waldenström macroglobulinemia died of renal and cardiac amyloidosis at 4 years. The patient with pleural amyloidosis and MM died of MM at 1 year, and the patient with tracheobronchial amyloidosis was alive at 3 years.

\section{Discussion}

We investigated patients with amyloidosis of the respiratory system to assess their clinical and radiological features, focusing especially on the deposition patterns, underlying precursor protein, and localised or systemic form. Of the five deposition patterns, nodular pulmonary amyloidosis is associated with the localised form, AL amyloidosis, MALT lymphoma, and Sjögren's syndrome and has an excellent prognosis. Three of the five patients with diffuse alveolar-septal amyloidosis were diagnosed by TBLB performed to investigate DAH or PCP, and four patients died within 3 years. Three of these five patients had no parenchymal shadow on chest CT after underlying DAH or PCP improved, and similarly, one patient with lung cancer had no CT findings of diffuse alveolar-septal amyloidosis. EBUS-TBNA was also a useful method of diagnosing mediastinal lymph node amyloidosis.

The differential diagnoses of nodular pulmonary amyloidosis based on CT imaging should include lung cancer, lung metastasis, tuberculoma, and cryptococcosis $[6,8,13]$. Therefore, histological examination 

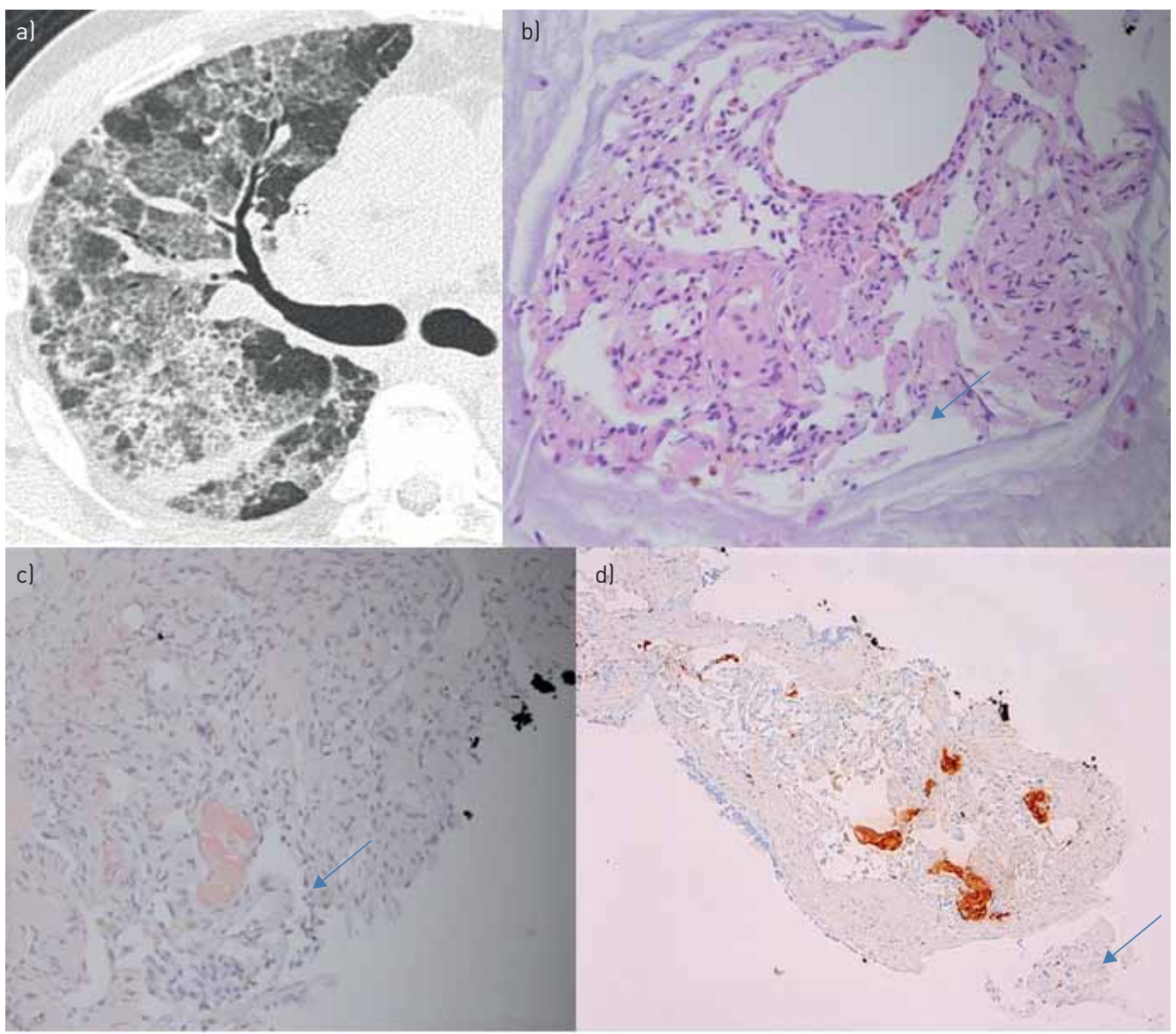

FIGURE 2 a) Axial high-resolution computed tomography image in the lung window and b-d) histologic findings of patient no. 14 with diffuse alveolar-septal amyloidosis presenting with diffuse alveolar haemorrhage. a) Patchy areas of ground-glass opacities and interlobular septal thickening present as a crazy-paving pattern. These opacities of diffuse alveolar haemorrhage disappeared within 2 weeks, after which a transbronchial lung biopsy was performed. b) Haematoxylin and eosin staining of a specimen from the transbronchial lung biopsy shows diffuse deposits of eosinophilic amorphous material in the alveolar-septal walls (blue arrow). c) Amorphous material was stained by Congo red stain (blue arrow). d) The precursor protein proved to be transthyretin by immunohistochemistry.

must be performed to distinguish among these disorders as much as possible. In addition, many experts now believe that most cases of nodular pulmonary amyloidosis result from an underlying lymphoproliferative disorder in the spectrum of MALT lymphoma $[19,20]$. One of our seven patients with nodular pulmonary amyloidosis had MALT lymphoma at diagnosis, and two developed MALT lymphoma during the follow-up period. Sjögren's syndrome is associated with pulmonary amyloidosis and lymphoproliferative disorders and manifests with multiple pulmonary cysts and multiple nodules [21-23]. Of our seven patients with AL localised amyloidosis, three had Sjögren's syndrome at diagnosis $(n=2)$ or during follow-up $(\mathrm{n}=1)$. All had multiple pulmonary cysts and multiple nodules.

Diffuse alveolar-septal amyloidosis is usually associated with systemic amyloidosis [5, 6]. All five of our patients with diffuse alveolar-septal amyloidosis had systemic amyloidosis. MGUS is reported to be present not only with systemic AL amyloidosis but also with ATTRwt amyloidosis [24]. One of our two patients with ATTRwt amyloidosis had MGUS.

Because pulmonary impairment rarely dominates the clinical picture, diffuse alveolar-septal amyloidosis is diagnosed as a post mortem finding. In a report of 76 patients with pulmonary amyloidosis [15], pulmonary vascular involvement was present in 74 , alveolar-septal amyloidosis in 59, and tracheobronchial involvement in 22 patients. Among all patients with pulmonary amyloidosis in this study, only one (1\%) patient, who manifested bilateral pulmonary nodules and masses, was diagnosed ante mortem; bronchoscopic biopsy revealed AL amyloidosis. Thus, it was not clinically suspected in most of the patients with alveolar-septal amyloidosis. Moreover, there are several case reports of pulmonary alveolar-septal amyloidosis causing DAH $[25,26]$. In the present study, two patients with DAH each had 
a)
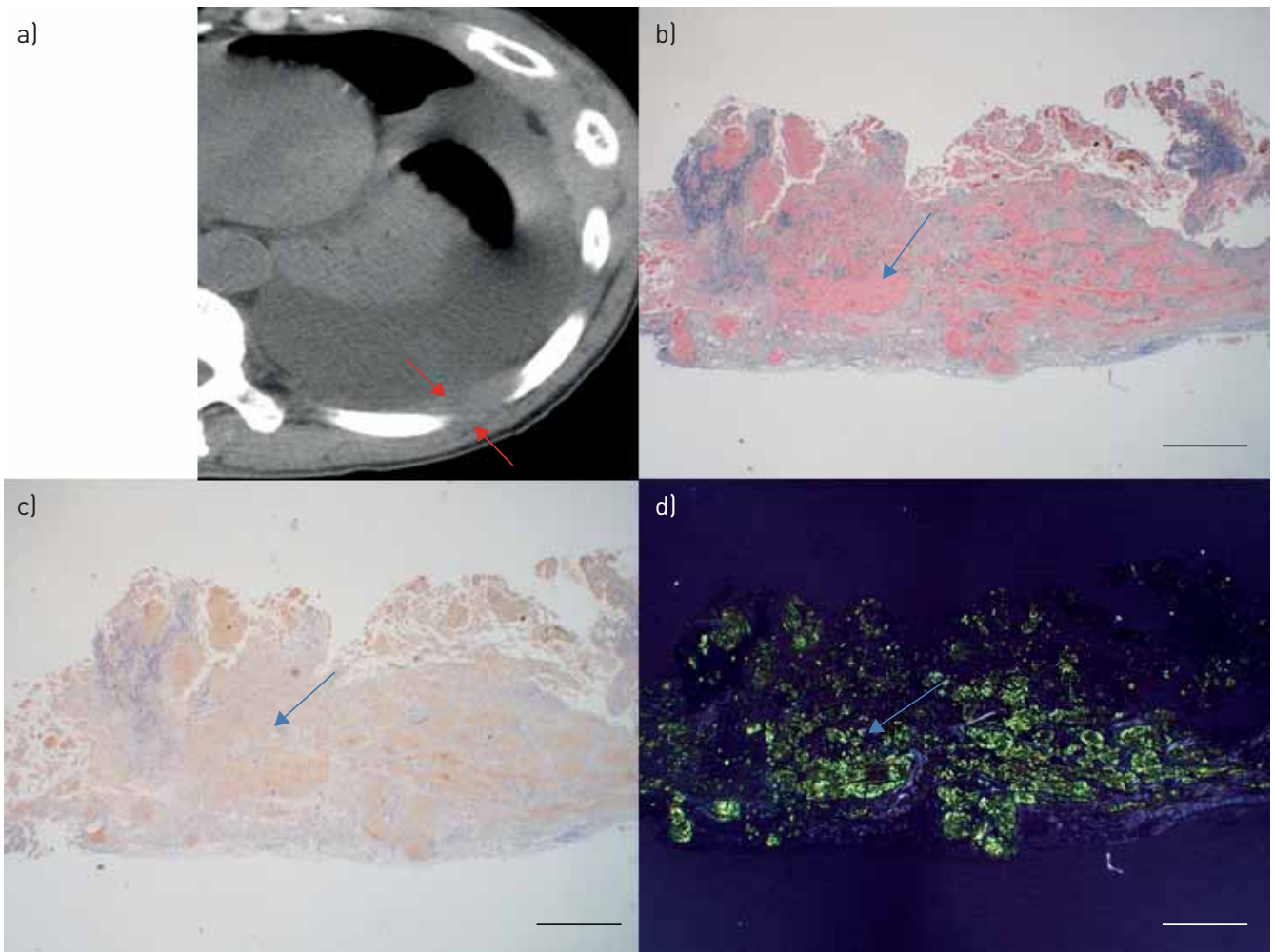

d)

FIGURE 3 a) Axial high-resolution computed tomography image in the mediastinal window and b-d) histologic findings of patient No. 10 with pleural amyloidosis presenting with dyspnoea. a) Pleural effusion and focal pleural thickening (red arrows) are seen in the left thorax. b) A specimen from the video-assisted thoracoscopic pleural biopsy in the upper right panel shows Congo red-stained deposits of amorphous material of an irregular oval shape (blue arrow). d) The right lower panel shows apple-green birefringence under polarised light. c) Precursor protein proved to be of immunoglobulin $\kappa$-light-chain origin by immunohistochemistry (lower left panel). CR: Congo red stain; IgLCк: immunoglobulin $\kappa$-light-chain; PL: polarised light.

MGUS and MM. DAH itself can be caused by a haematological disorder [26]. In clinical practice, we may have a negative attitude about performing TBLB in these patients, which may lead to difficulty in diagnosing diffuse alveolar-septal amyloidosis. In one patient with PCP combined with alveolar-septal amyloidosis, the latter was accidentally diagnosed by TBLB at the time of PCP diagnosis. Taken together, alveolar-septal amyloidosis was diagnosed by TBLB in three of our patients whose clinical presentation was DAH or PCP. TBLB is reported to be a useful and safe method for diagnosing amyloid lung disease [27].

Diffuse alveolar-septal amyloidosis is treated according to the underlying systemic amyloidosis. In AL amyloidosis, reducing the concentration of the circulating free light-chain translates in improvement of organ dysfunction and prolonged survival [28]. Systemic ATTRm amyloidosis is now treated with liver transplantation or the emerging TTR-modifying drug tafamidis [29].

Tracheobronchial amyloidosis is a localised type of AL amyloidosis whose management is largely dependent upon symptoms [30-34]. Pulmonary function testing showed that our patient with this condition had normal airflows, and no deterioration was observed during a 3-year follow-up with no specific therapy. Pleural effusion is common in systemic amyloidosis [35-38]. Pleural amyloidosis was diagnosed in one of our patients with MM. Hilar and mediastinal lymph node enlargement is common in primary amyloidosis but not in localised amyloidosis $[4,16]$. Mediastinal lymph node amyloidosis, which was diagnosed by EBUS-TBNA in two of our patients, was localised amyloidosis in one patient and systemic AL amyloidosis in the other two patients. There are several case reports of mediastinal lymph node amyloidosis diagnosed by EBUS-TBNA [39, 40]. Mediastinal lymphadenopathy is often associated with parenchymal lung disorder. In the present study, the possibility of complications of pulmonary amyloidosis could not be ruled out in the two patients with mediastinal lymph node amyloid deposition because they did not undergo lung biopsy.

The primary limitation of this study is its retrospective nature and limited number of patients. As amyloidosis of the respiratory system diagnosed ante mortem is very rare, we accumulated patients at two 
Japanese hospitals familiar with rare respiratory diseases. Thus, this report contains a relatively large number of patients. Second, although the proteomic method of mass spectrometric analysis of amyloidotic material has become the new gold standard for fibril typing, in our study, fibril typing was done by immunohistochemistry, which was the only method available for fibril typing during the study period.

In conclusion, not only nodular pulmonary amyloidosis, diffuse alveolar-septal amyloidosis, and tracheobronchial amyloidosis but also mediastinal lymph node amyloidosis and pleural amyloidosis should be considered in the differential diagnosis of amyloidosis of the respiratory system. Useful diagnostic methods include TBLB for diffuse alveolar-septal amyloidosis and EBUS-TBNA for mediastinal lymph node amyloidosis. Due to the rareness this condition, its many deposition patterns, underlying precursor proteins, and localised or systemic form, further accumulation of patients is necessary to better achieve a prompt diagnosis.

Acknowledgements: We sincerely thank Yoshiki Sekijima and Nagaaki Katoh of the Dept of Medicine (Neurology and Rheumatology), Shinshu University School of Medicine, Japan, and Yukio Ando and Taro Yamashita of the Amyloidosis Medical Practice Center, Kumamoto University Hospital, Kumamoto, Japan, for histological analysis and immunohistochemistry.

Conflict of interest: None declared.

Support statement: All work was performed at the Departments of Respiratory Medicine and Diagnostic Pathology, Saitama Cardiovascular and Respiratory Center and, the Department of Respiratory Medicine, Kanagawa Cardiovascular and Respiratory Center, and the Department of Pathobiology, Yokohama City University Graduate School of Medicine.

\section{References}

$1 \quad$ Wechalekar AD, Gillmore JD, Hawkins PN. Systemic amyloidosis. Lancet 2016; 387: 2641-2654.

2 Sipe JD, Benson MD, Buxbaum JN, et al. Amyloid fibril proteins and amyloidosis: chemical identification and clinical classification International Society of Amyloidosis 2016 Nomenclature Guidelines. Amyloid 2016; 23: 209-213.

3 Lane T, Pinney JH, Gilbertson JA, et al. Changing epidemiology of AA amyloidosis: clinical observations over 25 years at a single national referral centre. Amyloid 2017; 24: 162-166.

4 de Almeida RR, Zanetti G, Pereira E Silva JL, et al. Respiratory tract amyloidosis. State-of-the-art review with a focus on pulmonary involvement. Lung 2015; 193: 875-883.

$5 \quad$ Milani P, Basset M, Russo F, et al. The lung in amyloidosis. Eur Respir Rev 2017; 26: 170046.

6 Khoor A, Colby TV. Amyloidosis of the lung. Arch Pathol Lab Med 2017; 141: 247-254.

7 Utz JP, Swensen SJ, Gertz MA. Pulmonary amyloidosis. The Mayo Clinic experience from 1980 to 1993. Ann Intern Med 1996; 124: 407-413.

8 Pickford HA, Swensen SJ, Utz JP. Thoracic cross-sectional imaging of amyloidosis. AJR Am J Roentgenol 1997; 168: $351-355$.

9 Hui AN, Koss MN, Hochholzer L, et al. Amyloidosis presenting in the lower respiratory tract. Clinicopathologic, radiologic, immunohistochemical, and histochemical studies on 48 cases. Arch Pathol Lab Med 1986; 110: 212-218.

$10 \mathrm{Chu} \mathrm{H}$, Zhao L, Zhang Z, et al. Clinical characteristics of amyloidosis with isolated respiratory system involvement: a review of 13 cases. Ann Thorac Med 2012; 7: 243-249.

11 Westermark P, Bergström J, Solomon A, et al. Transthyretin-derived senile systemic amyloidosis: clinicopathologic and structural considerations. Amyloid 2003; 10: 48-54.

12 Scala R, Maccari U, Madioni C, et al. Amyloidosis involving the respiratory system: 5 years' experience of a multi-disciplinary group's activity. Ann Thorac Med 2015; 10: 212-216.

13 Czeyda-Pommersheim F, Hwang M, Chen SS, et al. Amyloidosis: modern cross-sectional imaging. Radiographics 2015; 35: 1381-1392.

14 Baumgart JV, Stuhlmann-Laeisz C, Hegenbart U, et al. Local vs. systemic pulmonary amyloidosis-impact on diagnostics and clinical management. Virchows Arch 2018; 473: 627-637.

15 Ussavarungsi K, Yi ES, Maleszewski JJ, et al. Clinical relevance of pulmonary amyloidosis: an analysis of 76 autopsy-derived cases. Eur Respir J 2017; 49: 1602313.

16 Mahmood S, Bridoux F, Venner CP, et al. Natural history and outcomes in localised immunoglobulin light-chain amyloidosis: a long-term observational study. Lancet Haematol 2015; 2: e241-e250.

17 Shimazaki C, Hata H, Iida S, et al. Nationwide survey of 741 patients with systemic amyloid light-chain amyloidosis in Japan. Intern Med 2018; 57: 181-187.

18 Nakagawa M, Sekijima Y, Yazaki M, et al. Carpal tunnel syndrome: a common initial symptom of systemic wild-type ATTR (ATTRwt) amyloidosis. Amyloid 2016; 23: 58-63.

19 Grogg KL, Aubry MC, Vrana JA, et al. Nodular pulmonary amyloidosis is characterized by localized immunoglobulin deposition and is frequently associated with an indolent B-cell lymphoproliferative disorder. Am J Surg Pathol 2013; 37: 406-412.

20 Lim JK, Lacy MQ, Kurtin PJ, et al. Pulmonary marginal zone lymphoma of MALT type as a cause of localised pulmonary amyloidosis. J Clin Pathol 2001; 54: 642-646.

21 Zamora AC, White DB, Sykes AM, et al. Amyloid-associated cystic lung disease. Chest 2016; 149: 1223-1233.

22 Rajagopala S, Singh N, Gupta K, et al. Pulmonary amyloidosis in Sjogren's syndrome: a case report and systematic review of the literature. Respirology 2010; 15: 860-866.

23 Jeong YJ, Lee KS, Chung MP, et al. Amyloidosis and lymphoproliferative disease in Sjögren syndrome: thin-section computed tomography findings and histopathologic comparisons. J Comput Assist Tomogr 2004; 28 776-781. 
33 Neben-Wittich MA, Foote RL, Kalra S. External beam radiation therapy for tracheobronchial amyloidosis. Chest 2007; 132: 262-267.

34 Moore A, Kramer MR, Silvern D, et al. Endobronchial brachytherapy-A novel approach for the management of airway amyloidosis. Brachytherapy 2018; 17: 966-972.

35 Berk JL, Keane J, Seldin DC, et al. Persistent pleural effusions in primary systemic amyloidosis: etiology and prognosis. Chest 2003; 124: 969-977.

36 Knapp MJ, Roggli VL, Kim J, et al. Pleural amyloidosis. Arch Pathol Lab Med 1988; 112: 57-60.

37 Kavuru MS, Adamo JP, Ahmad M, et al. Amyloidosis and pleural disease. Chest 1990; 98: 20-23.

38 Bontemps F, Tillie-Leblond I, Coppin MC, et al. Pleural amyloidosis: thoracoscopic aspects. Eur Respir J 1995; 8: 1025-1027.

39 Khor YH, Steinfort DP, Buchanan MR, et al. A 69-year-old smoker with mediastinal and hilar lymphadenopathy. Thorax 2010; 65: 132-138. 187.

40 Narechania S, Valent J, Farver C, et al. A 70-year-old man with large cervical and mediastinal lymphadenopathies. Chest 2015; 148: e8-e13. 